\title{
Advances in HOSM Control Design and Implementation for PEM Fuel Cell Systems
}

\author{
Cristian Kunusch* Paul F. Puleston* Miguel A.Mayosky* \\ Maria Serra** \\ * LEICI, Depto. de Electrotecnia, Universidad Nacional de La Plata, \\ calle 48 y $116 \mathrm{~s} / \mathrm{n}$ (CC 91), La Plata (B1900TAG), Argentina. \\ ** Institut de Robòtica i Informàtica Industrial (CSIC-UPC), \\ carrer Llorens i Artigas 4-6, Barcelona (08028), España.
}

\begin{abstract}
A second order sliding mode strategy to control the air supply and oxygen stoichiometry of a fuel cell based generation system is presented. The control design is accomplished from a complete model of a experimental plant that was previously developed by the authors and specially suited for nonlinear control issues. The resulting controller endows the system with enhanced dynamic characteristics and robustness to model uncertainties and external disturbances. Simulations and experimental results are provided, showing the feasibility and reliability of the approach.
\end{abstract}

Keywords: Fuel cell systems, nonlinear control, second order sliding modes, experimental results.

\section{INTRODUCTION}

A fuel cell is an electrochemical energy converter that transforms chemical energy or fuel directly into DC electricity [Barbir 2005]. Typically, these devices work as follows: the catalytic oxidation of hydrogen in an anode and the catalytic reduction of oxygen in a cathode creates a potential difference. Then, by means of an electrolyte that isolates electrically electrodes but allows protons transmission, the potential difference can be exploited by an external circuit. In addition to the electrical energy released, the by-products of the reaction are water and heat. Considering that the process is not subject to the Carnot principle, high energy efficiencies can be obtained both from the fuel cells and the whole generation system.

The concept of fuel cell (FC) dates from the mid 19th century, but only during the recent decades an intensive activity has been developed to increase the flexibility in the electric generation and to provide more simple and efficient distributed generation systems.

From the automatic control point of view, the task of improving the dynamic behavior and the efficiency of fuel cell based systems is particularly challenging, since there are several complex systems with high order nonlinear dynamics involved. For instance, only considering the air supply subsystem of a polymer electrolite membrane (PEM) fuel cell stack connected to a compressor, its behaviour can be described by a seventh order nonlinear model with many

* This research has been supported by the Agencia Española de Cooperación Internacional (AECI) under de project A/014833/07, Universidad Nacional de La Plata (UNLP), Universitat Politècnica de Catalunya (UPC), Comisión de Investigaciones Científicas de la Provincia de Buenos Aires (CICpBA) and Consejo de Investigaciones Científicas y Técnicas (CONICET). internal variables inaccessible to use in control algorithms. Besides, there are measurable and non-measurable disturbances that can affect the system operation, as well as model uncertainties. Moreover, nowadays there is little information in the open literature describing fuel cell systems models specially suitable for nonlinear control design.

In particular, a major challenge that must be faced from the automation area is the implementation of reliable control systems that ensure stability and performance, as well as robustness to model uncertainties and external perturbations. Among some of the advantages that offers the implementation of automation in fuel cell systems, it can be highlighted the humidity and oxygen stoichiometry control, which are one of the most important issues that have to overcome fuel cells systems nowadays [Pukrushpan et al. 2004]. In this way, a proficient control strategy with the aforementioned characteristics, would be able to optimize the system conversion efficiency, avoiding performance deterioration in the electrical variables (voltage and internal resistance) and possible irreversible damages in the polymeric membranes.

Accordingly, in the current work an air flow and oxygen stoichiometry control design and implementation of a laboratory fuel cell system is presented, where the control problem is solved through a higher order sliding mode (HOSM) controller. Among some of the advantages of this solution it can be highlighted the capability of system robust stabilization, finite time convergence to the sliding manifold and chattering reduction even in the presence of model uncertainties and disturbances [Fridman and Levant 2002, Bartolini et al. 1998, Boiko and Fridman 2005].

The work was conducted and organized in a way that the results and proposed methods can be straightforwardly 
extended to other fuel cell systems. Previous theoretical results based on an open literature model were presented in [Kunusch et al. 2009], where a feasibility study of second order sliding modes (SOSM) applied to fuel cell systems was conducted. In the current work, the presented simulation results are shown to be in reasonable agreement with the experimental data in a wide range of operation conditions, indicating that the control design can be successfully integrated into the system.

As in can be seen in Fig. 1, the main subsystems involved in the test plant under analysis comprises an air compressor, hydrogen and oxygen humidifiers, line heaters, back pressure regulators and a 7 -cell fuel cell stack (Fig. 1).

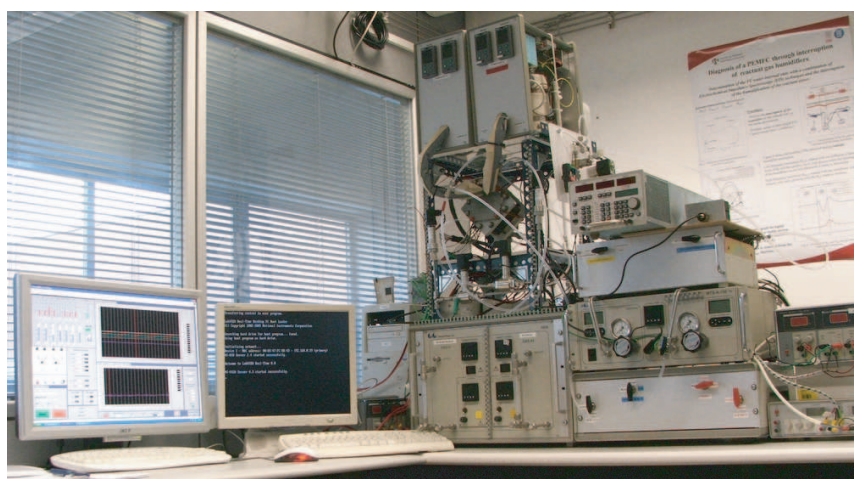

Fig. 1. Experimental laboratory test station

\section{SYSTEM MODEL}

Some of the technical specifications of the laboratory fuel cell system under study are as follows: the fuel cell stack is an ElectroChem ${ }^{\circledR}$ 7-cell stack with Nafion $115^{\circledR}$ membrane electrodes assemblies (MEAs) with a catalyst loading of $1 \mathrm{mg} / \mathrm{cm}^{2}$ of platinum, $50 \mathrm{~cm}^{2}$ of active area, $50 \mathrm{~W}$ of nominal power and $100 \mathrm{~W}$ peak power. Cellkraft ${ }^{\circledR}$ membrane exchange humidifiers are used to maintain proper humidity conditions inside the cells, which is crucial to ensure the optimal operation of a PEM membranes. The air compressor consists on a $12 \mathrm{~V}$ DC oil-free diaphragm vacuum pump. The line heaters and stack temperatures are controlled by a power station via decentralized PID controllers, allowing independent gas conditions (humidity and temperature) inside the stack.

The system modelling was performed combining theoretical modelling techniques and empirical analysis. In this way, models of the compressor, air supply manifold, cathode and anode humidifier, line heaters, fuel cell stack channels and membrane water transport were developed and experimentally validated [Kunusch et al. 2008]. In general terms, the work was firstly focused on obtaining a preliminary structure based on the physical laws that govern each subsystem presented in the following figure (Fig. 2)

Then, the model structures and parameters were adjusted in order to match the experimental data. To measure the required experimental data, different sensors were incorporated ad hoc into the system (see figure 2): a air mass flow meter (range $0-15 \mathrm{slpm}$ ) at the compressor output $\left(W_{c p}\right)$, a piezoresistive pressure transducer (range 0-6 barg) to mea-

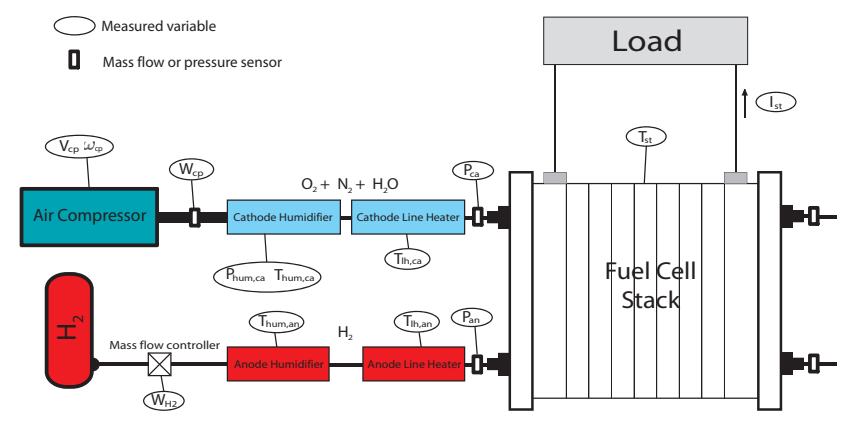

Fig. 2. Fuel cell system diagram

sure the cathode humidifier pressure $\left(P_{\text {hum }, c a}\right)$, piezoresistive differential pressure transducers (range 0-250 mbar) to measure the stack pressure drops $\left(P_{c a}\right.$ and $\left.P_{a n}\right)$, a tachometer (range 0-3000 rpm) on the motor shaft $\left(\omega_{c p}\right)$, a current clamp (range 0-3 A) and a voltage meter (range $0-15 \mathrm{~V})$ to measure the motor stator current $\left(I_{c p}\right)$ and voltage $\left(V_{c p}\right)$ respectively. Apart from that, temperature sensors were arranged in order to register the different temperatures of the system $\left(T_{s t}, T_{h u m, c a}, T_{l h, c a}, T_{h u m, a n}\right.$ and $\left.T_{l h, a n}\right)$. After algebraic manipulation of the physical model equations presented in [Kunusch et al. 2008], it can be obtained the following structure, suitable for nonlinear control design (see extended equations in Appendix A):

$$
\begin{gathered}
\dot{x}=F(x(t))+G \cdot u(t) \\
x \in \mathcal{R}^{7} ; u \in \mathcal{R} ; F: \mathcal{R}^{7} \rightarrow \mathcal{R}^{7}
\end{gathered}
$$

where $G=\left[\begin{array}{llll}K & 0 & \ldots & 0\end{array}\right]^{T}$ and the coordinates of the states vector can be summarized as follows:

- $x_{1}=\omega_{c p}$ : angular speed of the compressor motor.

- $x_{2}=m_{\text {hum }, c a}$ : mass of air in the cathode humidifier.

- $x_{3}=m_{o_{2}, c a}$ : mass of oxygen in the stack cathode.

- $x_{4}=m_{N_{2}, c a}$ : mass of nitrogen in the stack cathode.

- $x_{5}=m_{v_{2}, c a}$ : mass of vapor in the stack cathode.

- $x_{6}=m_{H_{2}, a n}$ : mass of hydrogen in the stack anode.

- $x_{7}=m_{v_{2}, a n}$ : mass of vapor in the stack anode.

The single control input considered in this study $(u(t))$ is the voltage of the DC motor stator $V_{c m}$.

\section{CONTROL OBJECTIVE}

The following stage in the control design procedure is to establish the control objective and, accordingly, define the sliding surface. In this particular case, the pursued objective is the optimization of the energy conversion of the fuel cell system, maximizing the net power generated by the system under different load conditions. Considering that the net power $\left(P_{n e t}\right)$ is defined as the electrical power delivered by the stack $\left(P_{s t}\right)$ minus the electrical power consumed by the compression subsystem, the system efficiency optimization can be achieved by regulating the air mass flow entering to the stack cathode at different load conditions. Fig. 3 presents the $P_{n e t}-W_{c p}$ map obtained from experimental tests conducted in the fuel cell laboratory at different stack currents $\left(I_{s t}\right)$.

It can be noticed that different air mass flows are required to maximize the net power in different working conditions, 


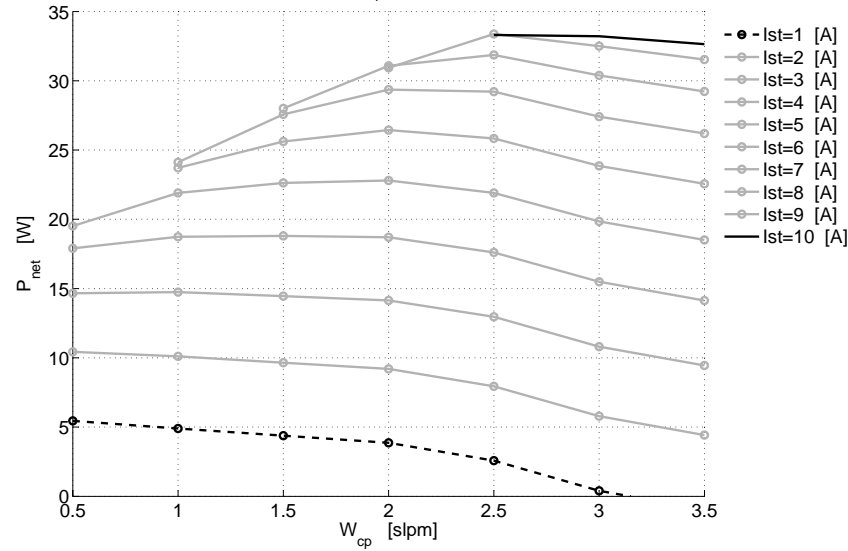

Fig. 3. System performance in different load conditions $\left(P_{\text {net }}\right.$ vs. $\left.W_{c p}\right)$

so the optimization problem can be reduced to an air regulation problem with a prescribed reference law.

Furthermore, in the next figure (Fig. 4) it can be appreciated that accomplishing such optimal comburent flow is equivalent to maintain the cathode line oxygen stoichiometry in an optimal value. This optimum value of $\lambda_{o_{2}}$ can be determined from a thorough off-line analysis of the open loop system, considering changes in the current demanded to the stack and a wide set of stoichiometry values (Fig. $4)$.

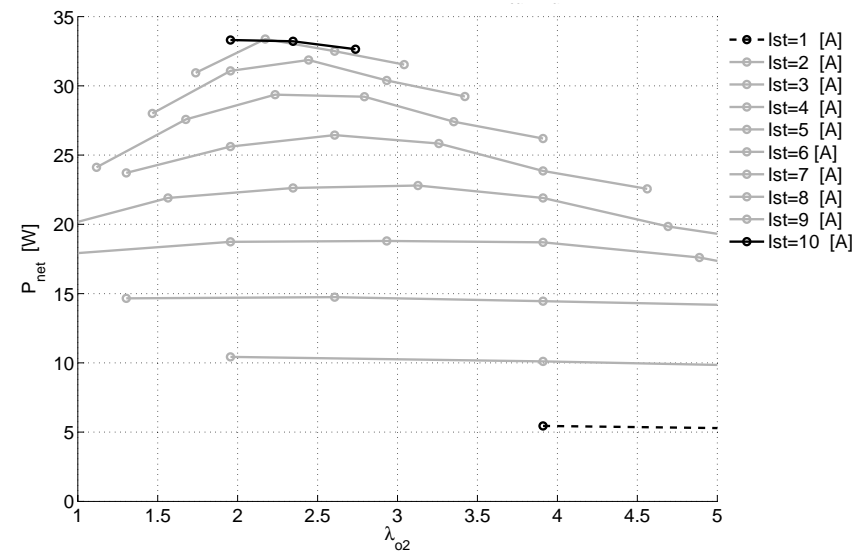

Fig. 4. System performance in different load conditions $\left(P_{n e t}\right.$ vs. $\left.\lambda_{o 2}\right)$

The oxygen stoichiometry or oxygen excess ratio is defined as:

$$
\lambda_{o_{2}}=\frac{W_{o_{2}, \text { in }}}{W_{o_{2}, \text { react }}}
$$

where $W_{o_{2}, \text { in }}$ is the oxygen partial flow in the cathode, which depends on the air flow released by the compressor $W_{c p}$ and the vapor injected by the humidifier. $W_{o_{2}, \text { react }}$ is the oxygen flow consumed in the reaction, so it can be directly related to the total stack current $\left(I_{s t}\right)$ :

$$
W_{o_{2}, \text { react }}=G_{o_{2}} \frac{n I_{s t}}{4 F}
$$

$G_{o 2}$ is the molar mass of oxygen, $n$ the total number of cells of the stack and $F$ the Faraday constant.
Once $\lambda_{o_{2}, o p t}$ is determined, the objective of keeping the oxygen excess ratio within optimal values can be written in terms of controlling the oxygen mass flow $\left(W_{o_{2}, i n}\right)$. Then, the following mass flow reference can be obtained from (2) and (3):

$$
W_{o_{2}, \text { in }, \text { ref }}=\lambda_{o_{2}, o p t} M_{o_{2}} \frac{n I_{s t}}{4 F}
$$

where tracking $W_{o_{2}, \text { in,ref }}$ effectively implies $\lambda_{o_{2}}=\lambda_{o_{2}, o p t}$. In the framework of the sliding mode theory, this control objective can be expressed as follows:

$$
S(x, t)=W_{c p}-W_{c p, r e f}
$$

where $s$ is the sliding variable that must be steered to zero and $W_{c p, r e f}$ is the compressor air mass flow reference. The expression of the latter can be readily obtained from the air mass flow reference. Given that the molar fraction of oxygen in the air $\left(\chi_{o 2}\right)$ is known, the desired mass flow of dry air can be directly computed from:

$$
W_{d r y \text { air }, r e f}=\frac{1}{\chi_{o 2}} W_{o_{2}, i n_{r e f}}=\frac{1}{\chi_{o 2}} \lambda_{o_{2}, o p t} M_{o_{2}} \frac{n I_{s t}}{4 F}
$$

Then, taking into account the relative humidity of the air $\left(\Omega_{a t m}\right)$, the final expression of the air mass reference results:

$$
W_{c p, r e f}=\left(1+\Omega_{a t m}\right) \frac{1}{\chi_{o 2}} \lambda_{o 2, o p t} M_{o 2} \frac{n I_{s t}}{4 F}
$$

Note that for stable ambient conditions, the reference only depends on a single measurable variable, i.e. the stack current $I_{s t}$.

\section{CONTROLLER DESIGN}

Analysing the Lie derivate of the sliding variable along the vector field $G\left(L_{G} S\right)$ and the Lie derivate of $L_{F} S$ along the vector field $G$ it can be concluded that the sliding variable $S$ has relative degree 1 . Note that $S$ does not explicitly depend on the control input, while $u$ appears in the $\dot{S}$ expression (see Appendix C).

$$
\begin{gathered}
L_{G} S(t, x)=\frac{\partial}{\partial u} S(t, x)=0 \\
L_{G} L_{F} S(t, x)=\frac{\partial}{\partial u} S(\dot{t}, x) \neq 0
\end{gathered}
$$

Considering that the sliding variable $S$ has relative degree one with respect to the control input $u$, it would be possible to implement a first order sliding mode control algorithm. However, in this particular fuel cell system this option does not represent the best alternative. Besides the chattering problem and the inconvenience of discontinuous voltage directly applied to the compressor, the use of such discontinuous control signal would also seriously deteriorate the net power performance, given that this output is zero relative degree. A better solution was developed designing a SOSM control to stabilize the system (1).

Thus, differentiating the sliding variable twice, the following relations are derived:

$$
\dot{S}=\frac{\partial}{\partial t} S(t, x)+\frac{\partial}{\partial x} S(t, x) \cdot(F(x)+G)
$$




$$
\begin{aligned}
& \ddot{S}=\frac{\partial}{\partial t} \dot{S}(t, x, u)+\frac{\partial}{\partial x} \dot{S}(t, x, u) \cdot(F(x)+G)+ \\
& +\frac{\partial}{\partial u} \dot{S}(t, x, u) \cdot \dot{u}(t)=\varphi(t, x, u)+\gamma(t, x, u) \dot{u}(t)
\end{aligned}
$$

For the system (1) with output $S(x, t)$, the expressions $\varphi(t, x, u)$ and $\gamma(t, x, u)$ can be globally bounded.

$$
\begin{gathered}
0<\Gamma_{m} \leq \gamma(t, x, u) \leq \Gamma_{M} \\
|\varphi(t, x, u)| \leq \Phi
\end{gathered}
$$

Then, the stabilization problem of the system (1) with input-output dynamics (11) can be solved through the solutions of the following equivalent differential inclusion by applying SOSM:

$$
\ddot{s} \in[-\Phi, \Phi]+\left[\Gamma_{m}, \Gamma_{M}\right] \dot{u}
$$

As it was settled in [Fridman and Levant 2002], it is necessary to previously define a proper control $u(t)$ that steers the sliding variable within a set such that the boundedness conditions on the sliding dynamics defined by conditions (12-13) are satisfied. Regarding this, in this paper a feedforward (FF) approach is proposed. It is defined a FF control term $u_{f f}$ that provides hitting the surface neighborhood $\left(S<\left|S_{0}\right|\right)$ where conditions (12-13) hold. This term is directly implemented through a polynomial which sets a mean control force $\left(u_{f f}\right)$, depending on the low frequency characteristic of the plant. Therefore the control action comprises two terms:

$$
u(t)=u_{f f}+u_{\text {sosm }}
$$

where the expression of $u_{f f}$ can be found in Appendix $\mathrm{C}$ and $u_{\text {sosm }}$ corresponds to a closed loop SOSM control action that was implemented through a super twisting controller. The main advantage of this particular algorithm relies on its robustness to parametric uncertainties and disturbances. Besides, during on-line operation it only requires knowledge of the sign of the sliding variable. Then the SOSM control term will be responsible of the robustness to model errors and external disturbances. The $u_{\text {sosm }}$ control expression is given as a sum of two components:

$$
\begin{aligned}
& u_{\text {sosm }}(t)=u_{1}(t)+u_{2}(t) \\
& \dot{u}_{1}(t)=-\gamma \operatorname{sign}(S) \\
& u_{2}(t)= \begin{cases}-\lambda\left|S_{0}\right|^{\rho} \operatorname{sign}(s) \text { if } & |S|>\left|S_{0}\right| \\
-\lambda|S|^{\rho} \operatorname{sign}(s) \text { if } & |S| \leq\left|S_{0}\right|\end{cases}
\end{aligned}
$$

where $\gamma, \lambda$ and $\rho$ are design parameters that where derived from the corresponding sufficient conditions for finite time convergence of the algorithm [Levant 1993]:

$$
\begin{aligned}
& \gamma>\frac{\Phi}{\Gamma_{m}} \\
& \lambda^{2} \geq \frac{4 \Phi}{\Gamma_{m}^{2}} \frac{\Gamma_{M}(\gamma+\Phi)}{\Gamma_{m}(\gamma-\Phi)} \\
& 0<\rho \leq 0.5
\end{aligned}
$$

All the controller parameters and system bounds can be found in the Appendix C.

\section{SIMULATION AND EXPERIMENTAL RESULTS}

The objective of this section is to demonstrate the performance of the proposed SOSM controller implemented in the fuel cell test station, considering external disturbances and different set points.

To begin with, the performance of the SOSM+FF controller was analysed by simulation in nominal operating conditions, considering the system (1) and a variable air mass flow reference. Subsequently, to assess the controller performance in real operation, the proposed control strategy was implemented in the laboratory test plant. In figure (5), the simulation and experimental results are presented showing the reliability and accuracy of the design methodology.

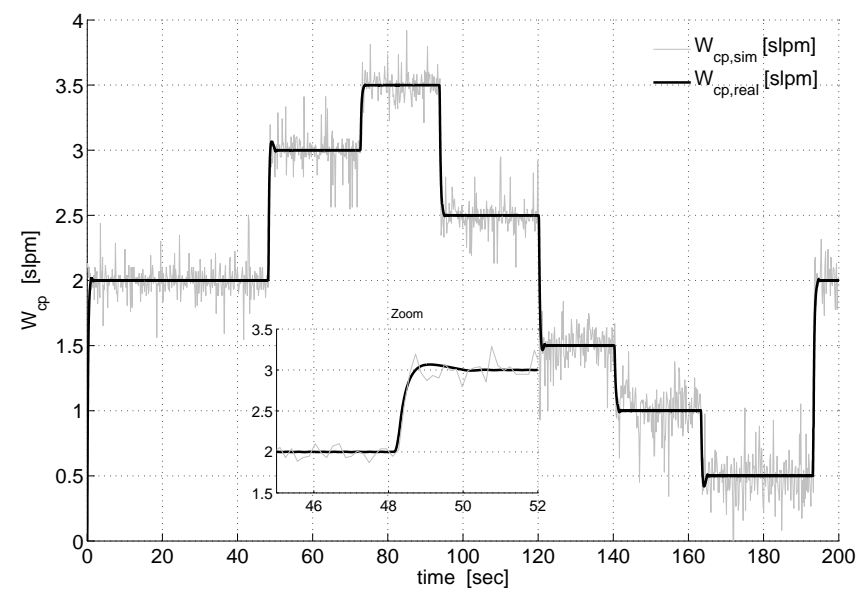

Fig. 5. $W_{c p}$ regulation with SOSM+FF controller: simulation and experimental results

It is interesting to observe that when no feedforward term is considered, the transient responses are noticeably affected for the same set of SOSM control parameters. In the following figure (Fig. 6) it can be appreciated the system performance when the feedforward term is omitted $\left(u_{f f}=0\right)$.

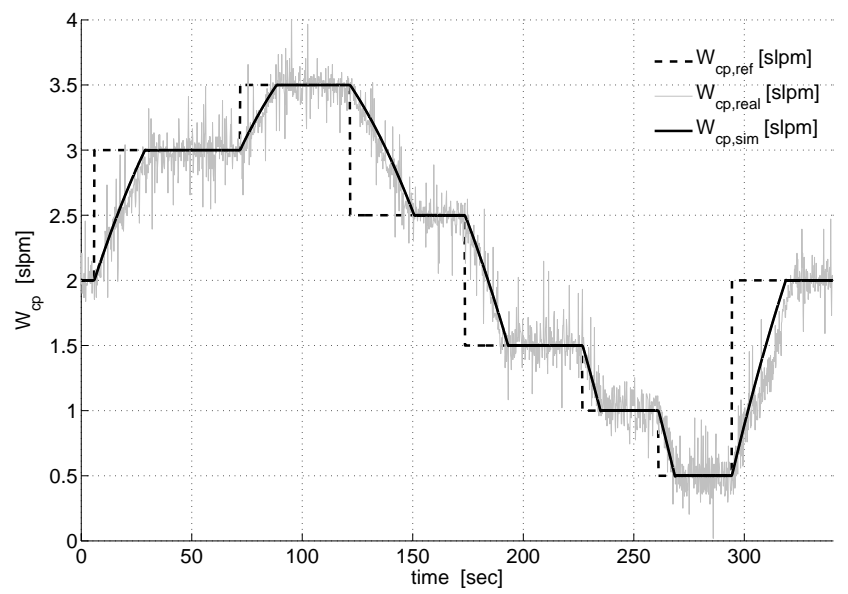

Fig. 6. $W_{c p}$ regulation with SOSM controller: simulation and experimental results

Finally, another other set of tests were performed in the PEM fuel cell test station, considering load current variations and external disturbances in the cathode line pressure. In these experiments, the control performance was assessed when the reference is given by a desired $\lambda_{o 2}$, see Fig. 7. 


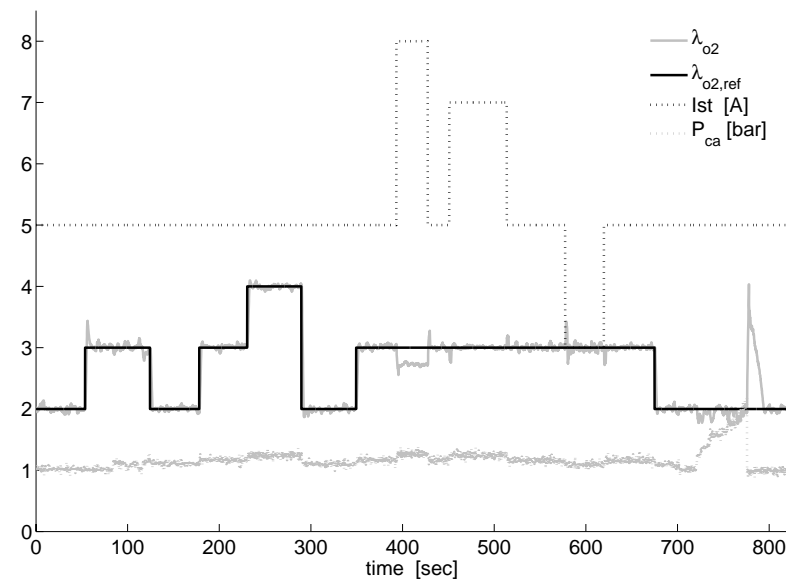

Fig. 7. $\lambda_{o 2}$ regulation: experimental results

Within the interval $0 \mathrm{~s}$ to $350 \mathrm{~s}$ variations in the $\lambda_{o 2}$ reference where considered. It can be noticed that the control objective is satisfactory accomplished and the simulation responses match the real behaviour of the plant. From 350 $\mathrm{s}$ on, load current variations where added while the stoichiometry reference is kept constant. Note that between $375 \mathrm{~s}$ and $425 \mathrm{~s}$, a saturation in the compressor actuator was forced. It can be appreciated that the control cannot temporarily keep the reference but the system recovers as soon as the saturation is overcome. This behaviour is because an extra algorithm was incorporated to avoid the integrator windup. At the end of the experiment $(t \simeq 700$ s) an external cathode pressure disturbance was included to examine the controller robustness features. This was artificially generated by manipulating the cathode back pressure regulator. Notice that when the system is strongly perturbed $(t \simeq 775 \mathrm{~s}$ ), the controller drives again the system trajectories to the sliding manifold. This is because the stability of the closed loop system is guaranteed given that the differential inclusion (14) is satisfied.

It is important to mention that the proposed SOSM+FF controller showed very good performance for a wide range of operation conditions, proving its robustness with respect to external disturbances and model uncertainties. Apart from the examples introduced in this section, extensive simulation and experimental analysis have been conducted and, in every case, highly satisfactory results have been obtained using the proposed controller set-up.

\section{CONCLUSION}

A control system that globally solves the oxygen stoichiometry problem of a fuel cell based generation system was designed and successfully implemented. A second order sliding mode strategy in conjunction with a feedforward action was developed to regulate the air flow and subsequently the oxygen stoichiometry. The main advantages of the adopted nonlinear control design approach applied to the FC system are as follows:

- solution of the robust stabilization problem avoiding chattering effects;

- enhanced dynamic characteristics;

- robustness to parameter uncertainties and external disturbances;
- guaranteed extended range of operation, in spite of the highly nonlinear nature of plant;

- the control law only depends on two measurable variables, namely the stack current and the compressor air flow, therefore no observer or state estimation is required;

- the structure of the algorithm is simple, thus low online computational burden is required.

The experimental tests were highly satisfactory, showing the suitability of the SOSM algorithm to control PEM type autonomous FC systems. Due to the encouraging results of the proposed strategy applied to this plant, it is planned to continue future works in the same research line aiming to improve, implement and compare new control strategies based on SOSM algorithms.

\section{ACKNOWLEDGEMENTS}

All the laboratory tests were performed at the Institut de Robòtica i Informàtica Industrial (CSIC-UPC) and only possible due to its advanced equipment and proficient technical staff.

\section{REFERENCES}

Barbir, F. (2005). PEM Fuel Cells. Elsevier.

Bartolini, G., Ferrara, A., and Usai, E. (1998). Chattering avoidance by second order sliding mode control. IEEE Transactions on Automatic Control, 43(2), 241-246.

Boiko, I. and Fridman, L. (2005). Analysis of chattering in continuous sliding-mode controllers. IEEE Transactions on Automatic Control, 50(9), 1442-1446.

Fridman, L. and Levant, A. (2002). Sliding Mode Control in Engineering, chapter 3 "Higher Order Sliding Modes", 53-101. Marcel Dekker, Inc.

Kunusch, C., Puleston, P., Mayosky, M., and Husar, A. (2008). Modelado dinámico y validación experimental de una pila de combustible PEM. CD publication, 8 pages. XIII Latin American Automatic Control Conference (CLCA 2008), Mérida, Venezuela.

Kunusch, C., Puleston, P., Mayosky, M., and Riera, J. (2009). Sliding mode strategy for PEM fuel cells stacks breathing control using a super-twisting algorithm. IEEE Transactions on Control System Technology, 17(1), 167-174.

Levant, A. (1993). Sliding order and sliding accuracy in sliding mode control. International Journal of Control, 58(6), 1247-1263.

Pukrushpan, J., Stefanopoulou, A., and Peng, H. (2004). Control of Fuel Cell Power Systems. Springer.

\section{Appendix A. SYSTEM MODEL}

\section{State-Space equations}

$$
\begin{aligned}
\dot{x}_{1} & =\left(m_{1}\left(U-m_{2} x_{1}\right)-x_{1} m_{3}+B_{0}+A_{00}+A_{10}\left(x_{2} m_{5}+m_{6}\right)+\right. \\
& +A_{20}\left(x_{2} m_{5}+m_{6}\right)^{2}+A_{01} x_{1}+A_{11}\left(x_{2} m_{5}+m_{6}\right) x_{1}+ \\
& \left.+A_{02} x_{1}^{2}\right) m_{4} \\
\dot{x}_{2}= & B_{00}+B_{10}\left(x_{2} m_{5}+m_{6}\right)+B_{20}\left(x_{2} m_{5}+m_{6}\right)^{2}+B_{01} x_{1}+ \\
& +B_{11}\left(x_{2} m_{5}+m_{6}\right) x_{1}+B_{02} x_{1}^{2}-b_{1}(x)^{3} C_{3}-b_{1}(x)^{2} C_{2}- \\
& -b_{1}(x) C_{1}-C_{0}
\end{aligned}
$$


$\dot{x}_{3}=\left(m_{9}\left(b_{1}(x)^{3} C_{3}+b_{1}(x)^{2} C_{2}+b_{1}(x) C_{1}+C_{0}\right) G_{a}{ }^{-1}\right.$

$\left(x_{2} m_{5}-m_{10}\right)^{-1}\left(1+\frac{m_{11}}{x_{2} m_{5}-m_{10}}\right)^{-1}+$

$\left.+\left(b_{1}(x)^{3} C_{3}+b_{1}(x)^{2} C_{2}+b_{1}(x) C_{1}+C_{0}\right)\left(1+\frac{m_{11}}{x_{2} m_{5}-m_{10}}\right)^{-1}\right) \dot{x}_{7}=W_{a n, i n}-W_{a n, i n}\left(1+\frac{G_{v} m_{17}}{G_{h}\left(b_{7}-m_{17}\right)}\right)^{-1}-$

$X_{o 2, c a, \text { in }}\left(1+\frac{m_{14}}{\left(x_{3} R_{0}+x_{4} R_{n}+x_{5} R_{v}\right) m_{8}-m_{12}}\right)^{-1}-$

$-K_{c a}\left(\left(x_{3} R_{o}+x_{4} R_{n}+x_{5} R_{v}\right) m_{8}-P_{a m b}\right) x_{3} R_{o} G_{O}$

$\left(1+G_{v} x_{5} R_{v}\left(\frac{x_{3} R_{o} G_{O}}{x_{3} R_{o}+x_{4} R_{n}}+\left(1-\frac{x_{3} R_{o}}{x_{3} R_{o}+x_{4} R_{n}}\right) G_{N}\right)^{-1}\right.$

$\left.\left(x_{3} R_{o}+x_{4} R_{n}\right)^{-1}\right)^{-1}\left(x_{3} R_{o}+x_{4} R_{n}\right)^{-1}$

$\left(\frac{x_{3} R_{o} G_{O}}{x_{3} R_{o}+x_{4} R_{n}}+\left(1-\frac{x_{3} R_{o}}{x_{3} R_{o}+x_{4} R_{n}}\right) G_{N}\right)^{-1}-1 / 4 \frac{G_{O} n I_{s t}}{F}$

$\dot{x}_{4}=\left(m_{9}\left(b_{1}(x)^{3} C_{3}+b_{1}(x)^{2} C_{2}+b_{1}(x) C_{1}+C_{0}\right)\right.$

$G_{a}^{-1}\left(x_{2} m_{5}-m_{10}\right)^{-1}\left(1+\frac{m_{11}}{x_{2} m_{5}-m_{10}}\right)^{-1}+$

$\left.+\left(b_{1}(x)^{3} C_{3}+b_{1}(x)^{2} C_{2}+b_{1}(x) C_{1}+C_{0}\right)\left(1+\frac{m_{11}}{x_{2} m_{5}-m_{10}}\right)^{-1}\right)$

$\left(1-X_{o 2, c a, i n}\right)\left(1+\frac{G_{v} m_{12}}{G_{a, c a, i n}\left(b_{2}(x)-m_{12}\right)}\right)^{-1}-$

$-\left(1-x_{3} m_{8} G_{O} b_{3}(x)^{-1}\left(\frac{x_{3} m_{8} G_{O}}{b_{3}(x)}+\left(1-\frac{x_{3} m_{8}}{b_{3}(x)}\right) G_{N}\right)^{-1}\right)$

$K_{c a, n}\left(b_{2}(x)-P_{a m b}\right)\left(1+G_{v} x_{5} R_{v} m_{8}\left(\frac{x_{3} m_{8} G_{O}}{b_{3}(x)}+\right.\right.$

$\left.\left.+\left(1-\frac{x_{3} m_{8}}{b_{3}(x)}\right) G_{N}\right)^{-1}\left(x_{3} R_{0} m_{8}+x_{4} R_{n} m_{8}\right)^{-1}\right)^{-1}$

$\dot{x}_{5}=G_{v} m_{12}\left(b_{1}(x)^{3} C_{3}+b_{1}(x)^{2} C_{2}+b_{1}(x) C_{1}+C_{0}\right)$

$G_{a}^{-1}\left(x_{2} m_{5}-m_{10}\right)^{-1}\left(1+\frac{G_{v} m_{10}}{G_{a}\left(x_{2} m_{5}-m_{10}\right)}\right)^{-1}+\frac{b_{4}(x)}{b_{5}(x)}-$

$-\left(\frac{G_{v} m_{12} b_{4}(x)}{G_{a}\left(x_{2} m_{5}-m_{10}\right) b_{5}(x)}+\frac{b_{4}(x)}{b_{5}(x)}\right)$

$\left(1+\frac{G_{v} m_{12}}{G_{a, c a, i n}\left(b_{2}(x)-m_{12}\right)}\right)^{-1}-K_{c a, n}\left(b_{2}(x)-P_{a m b}\right)+$

$+K_{c a, n}\left(b_{2}(x)-P_{a m b}\right)\left(1+G_{v} x_{5} R_{v} m_{8} b_{3}(x)^{-1}\left(\frac{x_{3} m_{8} G_{O}}{b_{3}(x)}+\right.\right.$

$\left.\left.+\left(1-\frac{x_{3} m_{8}}{b_{3}(x)}\right) G_{N}\right)^{-1} R_{o}^{-1}\right)^{-1}+1 / 2 \frac{G_{v} n I_{s t}}{F}+$

$+\left(\left(n_{0}+n_{1}\left(a_{0}+a_{1} b_{6}(x)+a_{2} b_{6}(x)^{2}+a_{3} b_{6}(x)^{3}\right)+\right.\right.$

$\left.+n_{2}\left(a_{0}+a_{1} b_{6}(x)+a_{2} b_{6}(x)^{2}+a_{3} b_{6}(x)^{3}\right)^{2}\right) I_{s t} / A_{f c} / F-$

$-D_{w}\left(\frac{\left(a_{0}+a_{1} x_{5} m_{16}+a_{2} x_{5}^{2} m_{16}^{2}+a_{3} x_{5}^{3} m_{16}{ }^{3}\right) \rho_{m, d r y}}{G_{m, d r y}}-\right.$

$\left.\left.-\frac{\left(a_{0}+a_{1} x_{7} m_{15}+a_{2} x_{7}{ }^{2} m_{15}{ }^{2}+a_{3} x_{7}^{3} m_{15}{ }^{3}\right) \rho_{m, d r y}}{G_{m, d r y}}\right) t_{m}{ }^{-1}\right)$

$G_{v} A_{f c} n$

$\dot{x}_{6}=W_{a n, i n}\left(1+\frac{G_{v} m_{1 \gamma}}{G_{h}\left(b_{\gamma}(x)-m_{1 \gamma}\right)}\right)^{-1}-K_{a n, n}\left(b_{\gamma}(x)-P_{a m b}\right)$

$$
\left(1+\frac{G_{v} x_{7} m_{19}}{G_{h} x_{6} m_{20}}\right)^{-1}-1 / 2 \frac{G_{h} n I_{s t}}{F}
$$

$-K_{a n, n}\left(b_{7}(x)-P_{a m b}\right)+K_{a n, n}\left(b_{7}(x)-P_{a m b}\right)\left(1+\frac{G_{v} x_{7} m_{19}}{G_{h} x_{6} m_{20}}\right)^{-1}-$

$-\left(\left(n_{0}+n_{1}\left(a_{0}+a_{1} b_{6}(x)+a_{2} b_{6}(x)^{2}+a_{3} b_{6}(x)^{3}\right)+\right.\right.$

$\left.+n_{2}\left(a_{0}+a_{1} b_{6}(x)+a_{2} b_{6}(x)^{2}+a_{3} b_{6}(x)^{3}\right)^{2}\right) I_{s t} / A_{f c} / F-$

$-D_{w}\left(\frac{\left(a_{0}+a_{1} x_{5} m_{16}+a_{2} x_{5}^{2} m_{16}{ }^{2}+a_{3} x_{5}^{3} m_{16}{ }^{3}\right) \rho_{m, d r y}}{G_{m, d r y}}-\right.$

$\left.\left.-\frac{\left(a_{0}+a_{1} x_{7} m_{15}+a_{2} x_{7}^{2} m_{15}^{2}+a_{3} x_{7}^{3} m_{15}^{3}\right) \rho_{m, d r y}}{G_{m, d r y}}\right) t_{m}{ }^{-1}\right)$

$G_{v} A_{f c} n$

Output

$y(t)=W_{c p}=B_{00}+B_{10}\left(x_{2} m_{5}+m_{6}\right)+B_{20}\left(x_{2} m_{5}+m_{6}\right)^{2}+$

$+B_{01} x_{1}+B_{11}\left(x_{2} m_{5}+m_{6}\right) x_{1}+B_{02} x_{1}^{2}$

Auxiliar functions

$b_{1}(x)=x_{2} m_{5}-\left(x_{3} R_{0}+x_{4} R_{n}+x_{5} R_{v}\right) m_{8}$

$b_{2}(x)=\left(x_{3} R_{0}+x_{4} R_{n}+x_{5} R_{v}\right) m_{8}$

$b_{3}(x)=\frac{x_{3} R_{o} m_{8}+x_{4} R_{n} m_{8}}{R_{o}}$

$b_{4}(x)=\left(x_{2} m_{5}-b_{2}\right)^{3} C_{3}+\left(x_{2} m_{5}-b_{2}\right)^{2} C_{2}+$

$$
+\left(x_{2} m_{5}-b_{2}\right) C_{1}+C_{0}
$$

$b_{5}(x)=1+\frac{G_{v} m_{10}}{G_{a}\left(x_{2} m_{5}-m_{10}\right)}$

$b_{6}(x)=1 / 2 x_{7} m_{15}+1 / 2 x_{5} m_{16}$

$b_{7}(x)=\left(x_{6} R_{h}+x_{7} R_{v}\right) m_{18}$

\section{Appendix B. MODEL PARAMETERS}

General parameters

$m_{1}=K_{\phi} / R ; m_{2}=K_{\phi} 30 / \pi ; m_{3}=B_{1} 30 / \pi ; m_{4}=\pi / 30 / J ; m_{5}=$ $T_{s m} R_{a} / V_{\text {hum }} ; m_{6}=-P_{\text {sat }, T_{s m}} R H_{a m b}+R H_{\text {hum }, c a} P_{\text {sat }, T_{\text {hum }, c a}} ;$ $m_{8}=T_{s t} / V_{c a} ; m_{9}=G_{v} R H_{\text {hum }, c a} P_{\text {sat }, T_{\text {hum }} a} ; m_{10}=P_{\text {sat }, T s m}$ $R H_{a m b} ; m_{11}=G_{v} P_{s a t, T_{s m}} R H_{a m b} / G_{a} ; m_{12}=R H_{h u m, c a} P_{s a t, T_{h u m, c a}} ;$ $m_{13}=R_{o} T_{s t} G_{O} ; m_{14}=G_{v} R H_{h u m, c a} P_{s a t, T_{h u m, c a}} / G_{a, c a, i n} ;$ $m_{15}=T_{s t} R_{v} / V_{a n} / P_{s a t, T_{l h, a n}} ; m_{16}=R_{v} T_{s t} / V_{c a} / P_{s a t, T_{l h, c a}} ;$ $m_{17}=R H_{a n, i n} P_{s a t, T_{l h, a n}} ; m_{18}=T_{s t} / V_{a n} ; m_{19}=T_{s t} R_{v} / V_{a n} ;$ $m_{20}=T_{s t} R_{h} / V_{a n}$

Physical parameters (SI units)

$\rho_{a}=1.29\left[\mathrm{~kg} / \mathrm{m}^{3}\right] ; \rho_{h}=0.08988\left[\mathrm{~kg} / \mathrm{m}^{3}\right] ; \rho_{v}=598\left[\mathrm{~kg} / \mathrm{m}^{3}\right] ;$ $G_{v}=0.01802[\mathrm{~kg} / \mathrm{mol}] ; G_{a}=0.029[\mathrm{~kg} / \mathrm{mol}] ; G_{h}=2.016 \times 10^{-3}$ $[\mathrm{kg} / \mathrm{mol}] ; G_{O}=32 \times 10^{-3}[\mathrm{~kg} / \mathrm{mol}] ; G_{N}=28 \times 10^{-3}[\mathrm{~kg} / \mathrm{mol}] ;$ $R_{a}=286.9[\mathrm{~N} . \mathrm{m} / \mathrm{kg} / \mathrm{K}] ; R_{h}=4.1243 \times 10^{3}[\mathrm{~N} . \mathrm{m} / \mathrm{kg} / \mathrm{K}] ; R_{o}=259.8$ $[\mathrm{N} . \mathrm{m} / \mathrm{kg} / \mathrm{K}] ; R_{n}=296.8[\mathrm{~N} . \mathrm{m} / \mathrm{kg} / \mathrm{K}] ; R_{v}=461.5[\mathrm{~N} . \mathrm{m} / \mathrm{kg} / \mathrm{K}] ;$ 
$F=96485[\mathrm{C} / \mathrm{mol}] ; R H_{a m b}=0.6 ; T_{a m b}=25+273[\mathrm{~K}] ; P_{a m b}=$ $1.01325 \times 10^{5}[\mathrm{~Pa}] ; Y_{o 2, c a, i n}=0.21 ; G_{a, c a, i n}=Y_{o 2, c a, i n} G_{O}+(1-$ $\left.Y_{o 2, c a, i n}\right) G_{N}[\mathrm{~kg} / \mathrm{mol}] ; X o 2_{c} a_{i} n=\left(Y_{o 2, c a, i n} G_{O}\right) /\left(Y_{o 2, c a, i n} G_{O}+\right.$ $\left.\left(1-Y_{o 2, c a, i n}\right) G_{N}\right) ; T_{s t}=60+273[\mathrm{~K}] ; T_{\text {hum }, c a}=55+273[\mathrm{~K}] ;$ $T_{l h, c a}=60+273[\mathrm{~K}] ; T_{\text {hum,an }}=55+273[\mathrm{~K}] ; T_{l h, a n}=60+273$ $[\mathrm{K}] ; P_{\text {sat }, \text { Tsm }}=P_{\text {sat }, \text { Thum }, \text { ca }}=P_{\text {sat }, \text { Thum }, a n}=0.13889 \times 10^{4}[\mathrm{~Pa}] ;$ $P_{\text {sat }, T l h, c a}=P_{\text {sat }, T l h, a n}=0.17622 \times 10^{4}[\mathrm{~Pa}] ; R H_{\text {hum }, \text { ca }}=0.95$; $R H_{\text {hum,an }}=0.95 ; R H_{a n, i n}=\left(P_{a m b}+R H_{\text {hum,an }} P_{\text {sat }, \text { Thum,an }}-\right.$ $\left.P_{a m b}\right) / P_{\text {sat }, T l h, a n} ; R=2.03[\mathrm{ohm}] ; L=2.12 \times 10^{-3}[\mathrm{H}] ; K_{\phi}=$ $0.0031[\mathrm{~V} / \mathrm{rpm}] ; B_{0}=4.1081 \times 10^{-4}[\mathrm{Nm}] ; B_{1}=4.1088 \times 10^{-7}$ $[\mathrm{Nm} / \mathrm{rpm}] ; J=0.12 \times 10^{-5}\left[\mathrm{Nm} . \mathrm{s}^{2}\right] ; V_{\text {hum }}=0.2 / 1000[1] ; n=7 ;$ $A_{f c}=50\left[\mathrm{~cm}^{2}\right] ; V_{c a}=2 / 1000[\mathrm{l}] ; K_{c a, n}=9.4062 \times 10^{-8}[\mathrm{~kg} / \mathrm{s} / \mathrm{bar}] ;$ $V_{a n}=2 / 1000[\mathrm{l}] ; D_{w}=5.43 \times 10^{-6}\left[\mathrm{~cm}^{2} / \mathrm{s}\right] ; K_{a n, n}=3.2769 \times$ $10^{-7}[\mathrm{~kg} / \mathrm{s} / \mathrm{bar}] ; t_{m}=0.0127[\mathrm{~cm}] ; \rho_{m, d r y}=0.002\left[\mathrm{~kg} / \mathrm{cm}^{3}\right] ;$ $G_{m, d r y}=1.1[\mathrm{~kg} / \mathrm{mol}] ; W_{a n, i n}=6.483 \times 10^{-6}[\mathrm{~kg} / \mathrm{s}]$

Polynomial coefficients

$A_{00}=0 ; A_{10}=5.8 \times 10^{-8} ; A_{20}=-1.3 \times 10^{-13} ; A_{01}=3.2557 \times$ $10^{-6} ; A_{11}=-2.8054 \times 10^{-11} ; A_{02}=-1.3782 \times 10^{-9}$

$B_{00}=4.8308 \times 10^{-5} ; B_{10}=-5.4281 \times 10^{-10} ; B_{20}=8.7957 \times 10^{-16}$; $B_{01}=3.4903 \times 10^{-7} ; B_{11}=3.5527 \times 10^{-13} ; B_{02}=-4.1107 \times 10^{-10}$

$C_{0}=1.083 \times 10^{-5} ; C_{1}=3.3510 \times 10^{-9} ; C_{2}=-5.4815 \times 10^{-14}$; $C_{3}=6.5622 \times 10^{-19}$

$a_{0}=0.043 ; a_{1}=17.81 ; a_{2}=-39.85 ; a_{3}=36.0$

$n_{0}=-3.4 \times 10^{-19} ; n_{1}=0.05 ; n_{2}=0.0029$

Appendix C. CONTROLLER DESIGN PARAMETERS

$u_{f f}=0.1014 W_{c p, r e f}^{6}-1.1412 W_{c p, r e f}^{5}+4.8303 W_{c p, r e f}^{4}-$

$-9.3370 W_{c p, r e f}^{3}+8.1430 W_{c p, r e f}^{2}-0.6129 W_{c p, r e f}+1.1526-1.35$

$\Phi=2.3 \times 10^{-5} ; \Gamma_{m}=0.002 ; \Gamma_{M}=0.0083 ; \lambda=10 ; \gamma=0.02 ;$ $S_{0}=0.01 ; \rho=0.5$; 